\title{
Inbreeding, outbreeding, infant growth, and size dimorphism in captive Indian rhinoceros (Rhinoceros unicornis)
}

\author{
Samuel Zschokke and Bruno Baur
}

\begin{abstract}
Effects of inbreeding and outbreeding on gestation period, birth mass, infant mortality, and growth, as well as the ontogeny of sexual size dimorphism, were analyzed in captive Indian rhinoceros (Rhinoceros unicornis L., 1758) using studbook data. Neither gestation period nor birth mass were affected by inbreeding. However, inbred calves grew slower and had a lower mortality rate than non-inbred ones. It is suggested that the severe bottleneck experienced in the early twentieth century by the Kaziranga population, from which most captive-born Indian rhinoceroses descend, resulted in strong inbreeding with consequent purging of recessive lethal alleles. Outbred individuals (offspring of matings between individuals from the Kaziranga and the Chitwan populations) had a higher infant mortality rate, suggesting that the two populations are genetically partially incompatible. Among captive individuals, adult males were found to be heavier $(2300 \mathrm{~kg})$ and larger (shoulder height $=172 \mathrm{~cm})$ than females $(1800 \mathrm{~kg}, 160 \mathrm{~cm})$. There were, however, no sex differences in gestation period, birth mass, or infant growth. This suggests that sexual dimorphism in adults is the result of a longer growth period in males rather than a difference in growth rate between the sexes.
\end{abstract}

\begin{abstract}
Résumé : Nous avons tenté de déterminer, à l'aide du registre généalogique des animaux, les effets de l'endogamie et de l'exogamie sur la période de gestation, la masse à la naissance, la mortalité infantile et la croissance, de même que sur l'ontologie du dimorphisme sexuel de la taille chez des rhinocéros des Indes (Rhinoceros unicornis L., 1758) gardés en captivité. L'endogamie s'est révélée sans effet sur la période de gestation ou sur la masse des petits à la naissance. Cependant, les jeunes rhinocéros consanguins se développent plus lentement et ont un taux de mortalité moins élevé que celui des animaux non consanguins. Nous croyons que l'étranglement qui s'est produit chez la population de Kaziranga au début du vingtième siècle a eu pour résultat une forte endogamie qui a épuré la population de ses allèles récessifs létaux. Les animaux obtenus par exogamie (fécondation croisée d'animaux de la population de Kaziranga et de celle de Chitwan) ont des taux de mortalité infantile plus élevés, ce qui semble indiquer que ces deux populations sont en partie génétiquement incompatibles. Parmi les animaux en captivité, les mâles adultes se sont avérés plus lourds $(2300 \mathrm{~kg}$ ) et plus grands (hauteur au garrot $=172 \mathrm{~cm})$ que les femelles $(1800 \mathrm{~kg}, 160 \mathrm{~cm})$. Cependant la durée de la gestation, la masse à la naissance et la croissance infantile sont semblables chez les mâles et les femelles. Cela semble indiquer que le dimorphisme sexuel chez les adultes est attribuable à la durée plus longue de la période de croissance des mâles plutôt qu'à une différence de taux de croissance entre mâles et femelles.
\end{abstract}

[Traduit par la Rédaction]

\section{Introduction}

The Indian or Greater one-horned rhinoceros (Rhinoceros unicornis L., 1758) is the fourth largest extant terrestrial mammal and the second largest of the five rhinoceros species (Owen-Smith 1988). In the wild, individuals generally live solitary or in mother-offspring groups. Breeding males have some degree of range exclusivity but no true territoriality (Laurie 1982). Fights between males are quite common and sometimes result in the death of one opponent (Dinerstein and Price 1991).

Received 22 January 2002. Accepted 4 October 2002.

Published on the NRC Research Press Web site at http://cjz.nrc.ca on 24 December 2002.

S. Zschokke ${ }^{1}$ and B. Baur. Department of Integrative Biology, Section of Conservation Biology (NLU), University of Basel, St. Johanns-Vorstadt 10, CH-4056 Basel, Switzerland.

${ }^{1}$ Corresponding author (e-mail: samuel.zschokke@alumni.ethz.ch).
In historical times (ca. 1400 AD), the Indian rhinoceros occurred along flood plains from northwestern Burma, across the Gangetic Plain, to the Indus River Valley in northern Pakistan (Blanford 1891; Laurie 1979; Rookmaaker 2000). Since the nineteenth century, land clearings fragmented the habitat and hunting reduced the populations, eliminating the Indian rhinoceros from all areas except the Chitwan Valley, lowland Bhutan, the Teesta Valley, West Bengal, and the Brahmaputra Valley in Assam (Dinerstein and McCracken 1990; Rookmaaker 1999). The population in the Brahmaputra Valley, Assam, was further reduced in the following decades, and in 1908, when hunting was banned, probably fewer than 20 individuals were left in the area of today's Kaziranga National Park (Ryhiner 1961; Laurie et al. 1983; Molur et al. 1995). In the Chitwan Valley in Nepal, a strong population persisted until about 1950; then, poaching and land clearing reduced the number to approximately 60-80 survivors in 1962 (Laurie 1979). Both the Kaziranga and the Chitwan populations have recovered from their bottlenecks. The Kaziranga population has even expanded into neighbouring areas (including Pobitora Wildlife Sanctuary and Orang Wildlife Sanctuary) and is 
now (1999) estimated to number 1770 individuals. The Chitwan population is estimated to consist of 600 individuals. Additionally, an estimated total of 135 individuals live in other areas in India and Nepal (Foose et al. 2000). The Indian rhinoceros has been classified as "endangered" by the International Union for Conservation of Nature and Natural Resources (IUCN) (Baillie and Groombridge 1996) and is listed in Appendix I of the Convention on International Trade in Endangered Species of Wild Fauna and Flora (CITES).

In captivity, the Indian rhinoceros breeds fairly well. Worldwide, the captive population consisted of 137 individuals (31 December 2001; Hlavacek and Studer 2002), most of which were imported from the Kaziranga population or descended from founders captured there after the bottleneck (Rookmaaker 1998; Zschokke et al. 1998). In captivity, males begin to reproduce at an age of 7-8 years and females at 4-5 years; individuals of both sexes live for 30-40 years (Wirz-Hlavacek et al. 1999). Dams give birth to a single calf. Sex ratio at birth is slightly male biased (57\% males, $n=170$; WirzHlavacek et al. 2001). In contrast with many other mammal species (Ballou and Ralls 1982), inbreeding does not seem to increase infant mortality in the Indian rhinoceros (WirzHlavacek et al. 2001; present study).

Inbreeding is generally known to reduce vitality in captive and wild populations (Ralls et al. 1988; Crnokrak and Roff 1999). Negative effects of inbreeding are mainly a result of recessive deleterious alleles, which are more likely to be homozygous in inbred individuals (Charlesworth and Charlesworth 1987). Population bottlenecks, as experienced by the Kaziranga population of the Indian rhinoceros, are known to increase the level of inbreeding and may subsequently purge deleterious alleles (Barrett and Charlesworth 1991; Saccheri et al. 1996).

Negative effects of outbreeding (mating of very distantly related individuals) are thought to be the result of disruption of complexes of interacting genes that have jointly evolved, of mixing of genomes adapted to different environments (Templeton 1986; Waser 1993), or of physical or physiological incompatibilities of mother and offspring during gestation and birth. Outbreeding depression is most likely to occur when individuals from genetically differentiated populations mate. However, empirical evidence for outbreeding depression is rare (Baur and Baur 1992; Marshall and Spalton 2000).

Sexual size dimorphism in adults occurs in most mammals (Ralls 1977). In species where males are larger than females, size dimorphism is usually explained by sexual selection, in particular by male competition for females, territories, or other resources needed to reproduce. There is abundant evidence from mammals that large size gives an advantage in male contests (Clutton-Brock 1991; Andersson 1994). In many species, however, it is not clear how size dimorphism develops: mothers may invest more resources into sons during gestation or lactation, males may grow faster than females at all ages (even in species lacking prolonged parental care), or both sexes show equal growth rates, but males reach maturity later.

Despite a great interest, information concerning the life history of the Indian rhinoceros is restricted to a few case studies with a limited sample size, which do not allow a general assessment. In addition, large endangered species like the Indian rhinoceros are not amenable to experimental investigations. Fortunately, zoological gardens offer the opportunity to study individuals of these species throughout their lives. In this way, data on life-history traits, which otherwise would not be available, can be collected and analyzed and the findings can be used to improve conservation efforts in endangered species (e.g., Lacy et al. 1993).

In the present study, we examined effects of inbreeding and outbreeding on various life-history traits in captive Indian rhinoceroses. We also investigated the ontogeny of size dimorphism in captive Indian rhinoceroses. In particular, we asked the following questions. ( $i$ ) Are there any effects of inbreeding or outbreeding on gestation period, birth mass, infant growth rate, and infant mortality? (ii) Are there any sex differences in gestation period, birth mass, infant growth rate, and infant mortality?

\section{Materials and methods}

\section{Data collection}

Data on births, deaths, and ancestry of individual Indian rhinoceroses were taken from the latest update of the international studbook (Hlavacek and Studer 2002). Data on gestation period, birth mass, mass at different ages, and adult shoulder height of captive Indian rhinoceroses were obtained from the following sources: studbook data (G. Hlavacek, personal communication), published reports and books (Tong 1960; Lang 1961; Reynolds 1961; Chowdhury 1966; Hagenbeck 1966; Lang 1967; Hagenbeck 1969; Krishne Gowda 1969; Bhatia and Desai 1975; Buechner et al. 1975; Lang et al. 1977; Dutta 1991; Tobler 1993; Rookmaaker 1998; Jonauskas and Liparte 2000; von Houwald 2001), and questionnaires received from the zoos listed in the Acknowledgements. In this way, we compiled data on the gestation period of 106 individuals and on the birth mass of 82 individuals. Of 64 individuals, both gestation period and birth mass were known. Infant growth rates were estimated from the mass increase during the first 2 months of life. Such estimates were available for 19 individuals.

For comparative analyses, infant mortality was considered over the first 6 months of life; stillbirths and individuals that died before they were 6 months old were considered infant deaths. Abortions (gestation <400 days) were excluded from all analyses. Inbreeding coefficients were calculated from the studbook pedigree using the method described in Ballou (1983). This approach is based on the assumption that all founder individuals are unrelated, and therefore, founders and offspring of founders (unless the founder was mated with its own earlier offspring) have an inbreeding coefficient of $f=$ 0 . Individuals were classified either as inbred $(f>0)$ or as non-inbred $(f=0)$.

Individuals with one parent from the Chitwan population and one parent from the Kaziranga population were considered outbred, whereas individuals with both parents from the Kaziranga population were considered non-outbred (so far, no individuals with both parents from the Chitwan population have been born in captivity, and no outbred individual has reproduced). We use "zoo generation" to distinguish between calves of wild-born dams (first zoo generation) and calves of captive-born dams (second and subsequent zoo generation). Since zoo generation and inbreeding of mother are strongly 
linked (calves of a wild-born dam by definition cannot have an inbred mother), the two factors were combined into a single factor (status) for analysis.

Individuals older than 7 years were considered adult. Mass and shoulder height measurements of adults were averaged if several measurements were available for the same individual.

\section{Data analysis}

Influences of inbreeding of calf, status (combination of zoo generation and inbreeding of mother, see above), outbreeding, sex, parity, father's age, mother's age, and zoo on gestation period, birth mass, and infant growth were tested with ANCOVAs without interactions. The model was stepwisereduced by eliminating factors with $F<1.0$ (McCullagh and Nelder 1989). Where the factor status was not eliminated, a contrast analysis was used to separately evaluate the influence of zoo generation and inbreeding of mother (Rosenthal and Rosnov 1985).

The relationship between gestation period and birth mass was assessed using linear regression. The influence of inbreeding of calf, status, outbreeding, sex, parity, father's age, mother's age, zoo generation, and zoo on infant mortality was tested using a logistic regression calculated with likelihood ratios. To evaluate the influence of zoo generation and inbreeding of mother separately, the test was repeated twice with a reduced dataset: first, only offspring of non-inbred mothers were considered to examine the influence of zoo generation; second, only offspring of zoo-born dams were considered to examine the influence of inbreeding of mother. The relationship between year of birth and mortality was assessed with a logistic regression on non-inbred offspring (Kalinowski et al. 1999).

The analysis described above does not take into consideration that related individuals cannot be considered entirely independent units. Most captive Indian rhinoceroses are related to each other (Zschokke et al. 1998), and eliminating all but the entirely unrelated offspring would reduce the dataset so much that no analyses would be possible. To reduce the dependence of data points, we additionally compared average gestation period, average birth mass, mortality rate (arcsine transformed), and average growth rate among all families (full-sib groups) using an ANOVA with the factors inbreeding of calf, status, outbreeding, and zoo. The $p$ values of these analyses (indicated as $p^{\prime}$ ) were used to corroborate the findings of the analyses at the level of individuals described above.

Unpaired $t$ tests were used to assess the relationship between sex of a calf and subsequent interbirth interval and to compare adult mass and size between males and females. Due to missing values, sample sizes differ between tests. All statistical tests were calculated using JMP vers. 3.2.2 for Macintosh (SAS Institute Inc. 1997). Descriptive data are presented as overall mean \pm SD with minimum and maximum in parentheses.

\section{Results}

\section{Gestation period and birth mass}

The gestation period averaged $479.1 \pm 9.9$ (425-496) days $(n=106)$. Outbred calves had a shorter gestation period (471.5 \pm 18.5 days, $n=10)$ than non-outbred calves $(479.9 \pm$
Table 1. Summary of the reduced ANOVAs testing various factors that influence Indian rhinoceros (Rhinoceros unicornis) gestation period.

\begin{tabular}{lrrrrl}
\hline Source & df & \multicolumn{1}{c}{ MS } & \multicolumn{1}{c}{$F$} & \multicolumn{1}{c}{$p$} & \multicolumn{1}{c}{$p^{\prime}$} \\
\hline Outbreeding & 1 & 1396.5 & 22.36 & $<0.001$ & $<0.001$ \\
Sex & 1 & 165.9 & 2.66 & 0.107 & - \\
Parity & 1 & 435.8 & 6.98 & 0.010 & - \\
Zoo & 17 & 236.2 & 3.78 & $<0.001$ & 0.017 \\
Error & 83 & 62.5 & & & \\
\hline
\end{tabular}

\footnotetext{
Note: $p$ values result from the analysis at the individual level and $p^{\prime}$ values from the analysis at the family $(n=43)$ level. During stepwise reduction, the factors inbreeding of calf, status (zoo generation and inbreeding of mother), father's age, and mother's age were eliminated. - , not testable.
}

8.3 days, $n=96$ ), and primiparous calves had a shorter gestation period ( $475.5 \pm 14.6$ days, $n=26)$ than multiparous calves (480.2 \pm 7.6 days, $n=78)$ (Table 1$)$. Additionally, the gestation period differed among the zoos in which the calves were born. The first two comparisons were strongly influenced by one primiparous, outbred individual (studbook No. 269) with a gestation period of only 425 days. When we omitted this individual from the analysis, the difference in gestation period between outbred (476.7 \pm 9.3 days, $n=9)$ and nonoutbred calves (479.9 \pm 8.3 days, $n=96)$ was smaller (ANOVA, $p=0.022, p^{\prime}=0.014$ ), and there was no longer a significant difference in gestation period between primiparous and multiparous calves $(p=0.052)$.

The average birth mass was $64.5 \pm 9.7(44-91) \mathrm{kg}(n=$ 82). Primiparous calves were lighter $(56.6 \pm 6.5 \mathrm{~kg}, n=23)$ than multiparous calves $(67.4 \pm 9.1 \mathrm{~kg}, n=57)$ (Fig. 1 , Table 2). The analysis at the individual level also suggested that calves of wild-born dams (first zoo generation, $61.8 \pm$ $10.7 \mathrm{~kg}, n=21$ ) were lighter than those of captive-born dams $(65.5 \pm 9.3 \mathrm{~kg}, n=61)$ and that the birth mass differed among zoos. However, these results were not confirmed in the analysis at the family level (Table 2).

We found no relationship between gestation period and birth mass $\left(r^{2}=0.019, n=64, p=0.283\right)$. Calves with a low birth mass were observed even after long gestation periods (Fig. 2).

\section{Infant mortality}

Infant mortality was on average $20.0 \%(n=170)$. Inbred calves had a lower mortality rate $(14 \%, n=44)$ than noninbred calves $(22 \%, n=126)$, outbred calves had a higher mortality rate $(42 \%, n=12)$ than non-outbred calves $(18 \%$, $n=158)$, and primiparous calves had a higher mortality rate $(31 \%, n=45)$ than multiparous calves $(16 \%, n=118)$ (Table 3$)$. The logistic regression also suggested that infant mortality was lower in calves of wild-born dams (first zoo generation, $17 \%, n=58$ ) than in calves of captive-born dams $(21 \%, n=112)$. However, this result was not confirmed in the analysis at the family level. Furthermore, infant mortality rates decreased with age of the father but increased with age of the mother. Infant mortality also differed among zoos (Table 3).

We found no relationship between year of birth and juvenile mortality (logistic regression, $r^{2}<0.001, p=0.848$ ). However, infant mortality was linked to birth mass; $58 \%$ $(n=24)$ of the calves with a birth mass of $<60 \mathrm{~kg}$ died 
Fig. 1. Gestation period $(a)$ and birth mass $(b)$ of the first four calves of five Indian rhinoceros (Rhinoceros unicornis) dams. In all five dams, the birth mass of all first and of all second offspring was similar, even though three dams were between 4 and 5 years old when they gave birth to the first offspring and the other two dams were between 8 and 9 years old.
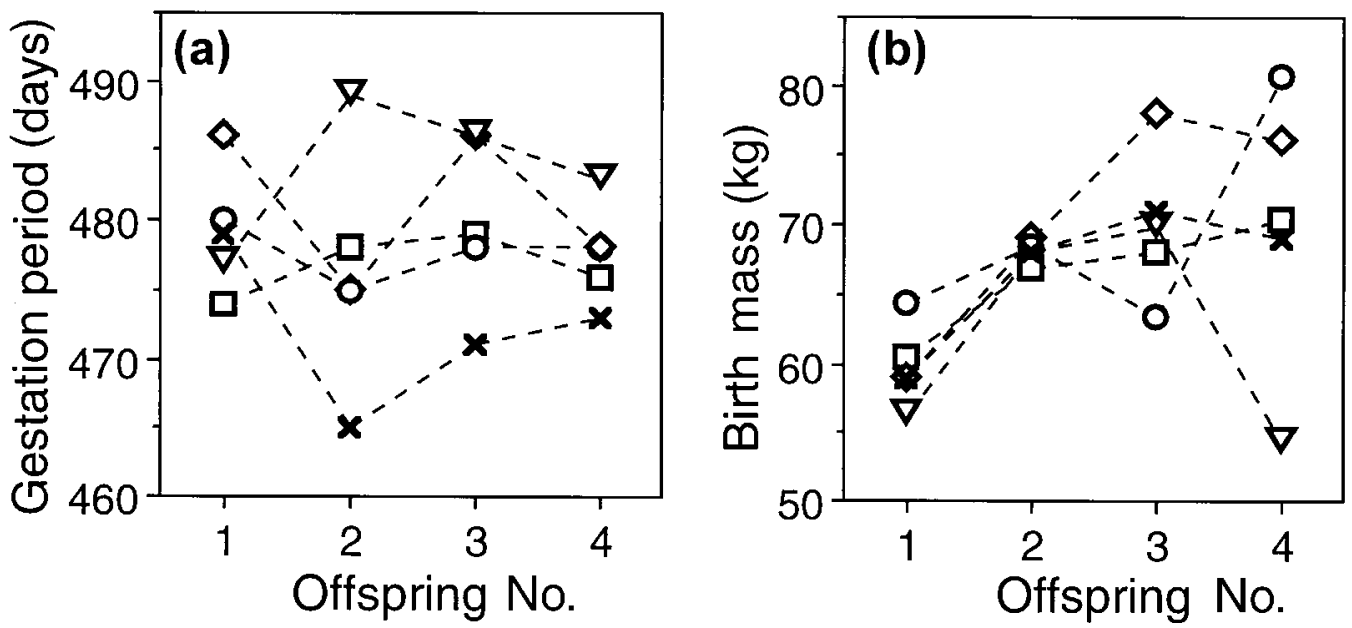

Table 2. Summary of the reduced AN(C)OVAs testing various factors that influence Indian rhinoceros birth mass.

\begin{tabular}{lrrrcl}
\hline Source & df & \multicolumn{1}{c}{ MS } & \multicolumn{1}{l}{$F$} & \multicolumn{1}{l}{$p$} & $p^{\prime}$ \\
\hline Inbreeding of calf & 1 & 53.1 & 1.05 & 0.311 & Eliminated $^{a}$ \\
Status & 2 & 164.7 & 3.24 & 0.046 & Eliminated $^{a}$ \\
Outbreeding & & & & $\begin{array}{l}\text { Eliminated } \\
a\end{array}$ & 0.303 \\
Parity & 1 & 651.7 & 12.82 & $<0.001$ & - \\
Father's age (covariate) & 1 & 74.4 & 1.46 & 0.231 & - \\
Zoo & 14 & 152.0 & 2.99 & 0.002 & 0.235 \\
Error & 60 & 50.8 & & & \\
\hline
\end{tabular}

Note: $p$ values result from the analysis at the individual level and $p^{\prime}$ values from the analysis at the family $(n=37)$ level. During stepwise reduction, the factors outbreeding, sex, and mother's age were eliminated. A contrast analysis examining the factor status (zoo generation and inbreeding of mother) at the individual level showed that zoo generation $(p=0.014)$ but not inbreeding of mother $(p=0.985)$ influenced the birth mass. -, not testable.

${ }^{a}$ Eliminated during stepwise reduction.

within 6 months, in contrast with $14 \%(n=56)$ of the calves weighing $\geq 60 \mathrm{~kg}$ (Table 4).

\section{Infant growth}

Infant growth of Indian rhinoceroses was found to be fairly linear during the first year with average daily mass gains of $1.67 \mathrm{~kg}$ (Fig. 3). At an age of 2 months, the average mass was $182.1 \pm 27.6(112-214) \mathrm{kg}(n=21)$.

Indian rhinoceroses increased their mass during the first 2 months of their lives by an average factor of $2.74 \pm 0.18$ (2.43-3.01) $(n=19)$. Inbred calves grew slower $(2.49 \pm$ $0.10, n=4)$ than non-inbred calves $(2.81 \pm 0.13, n=15)$ (Table 5, top panel in Fig. 3).

The sex of a calf did not influence the interval to the subsequent birth (intervals $\log$ transformed, $t=0.02$, df $=113$, $p=0.784)$.

\section{Adult size and sexual dimorphism}

Adult males were found to be $30 \%$ heavier $(2316 \pm 276$ $(1825-2800) \mathrm{kg}, n=12)$ than adult females $(1787 \pm 327$ $(1270-2300) \mathrm{kg}, n=11)(t=4.21, p<0.001)$. Adult males also had larger shoulder heights $(172 \pm 14(147-195) \mathrm{cm}$, $n=18)$ than adult females $(160 \pm 6(149-172) \mathrm{cm}, n=13)$ $(t=2.86, p=0.008)$. We found no differences in mass or size between wild-born and captive-born individuals or between inbred and non-inbred individuals.

\section{Discussion}

\section{Inbreeding}

The present study shows that inbreeding in the Indian rhinoceros does not influence gestation period or birth mass, nor does it increase infant mortality. These findings contrast other studies reporting reduced birth mass and increased infant mortality in inbred offspring in numerous other mammal species (reviewed in Ralls et al. 1979; also see Ballou and Ralls 1982; Coltman et al. 1998; Zschokke and Steck 2001). The present study could thus not confirm the tentative negative effects of inbreeding on infant mortality and gestation period in the Indian rhinoceros found in an earlier study (Baur and Studer 1995), which was based on a smaller dataset. Most interestingly, however, the present study showed for the first time that inbreeding reduces infant growth in the Indian rhinoceros.

Most of the captive-born Indian rhinoceroses (93\%) descend from the Kaziranga population, which went through a 
Fig. 2. Scatterplot of birth mass against gestation period in captive Indian rhinoceroses (squares refer to male and circles to female calves). Individuals that survived the first 6 months are indicated by solid symbols and those that died by open symbols.

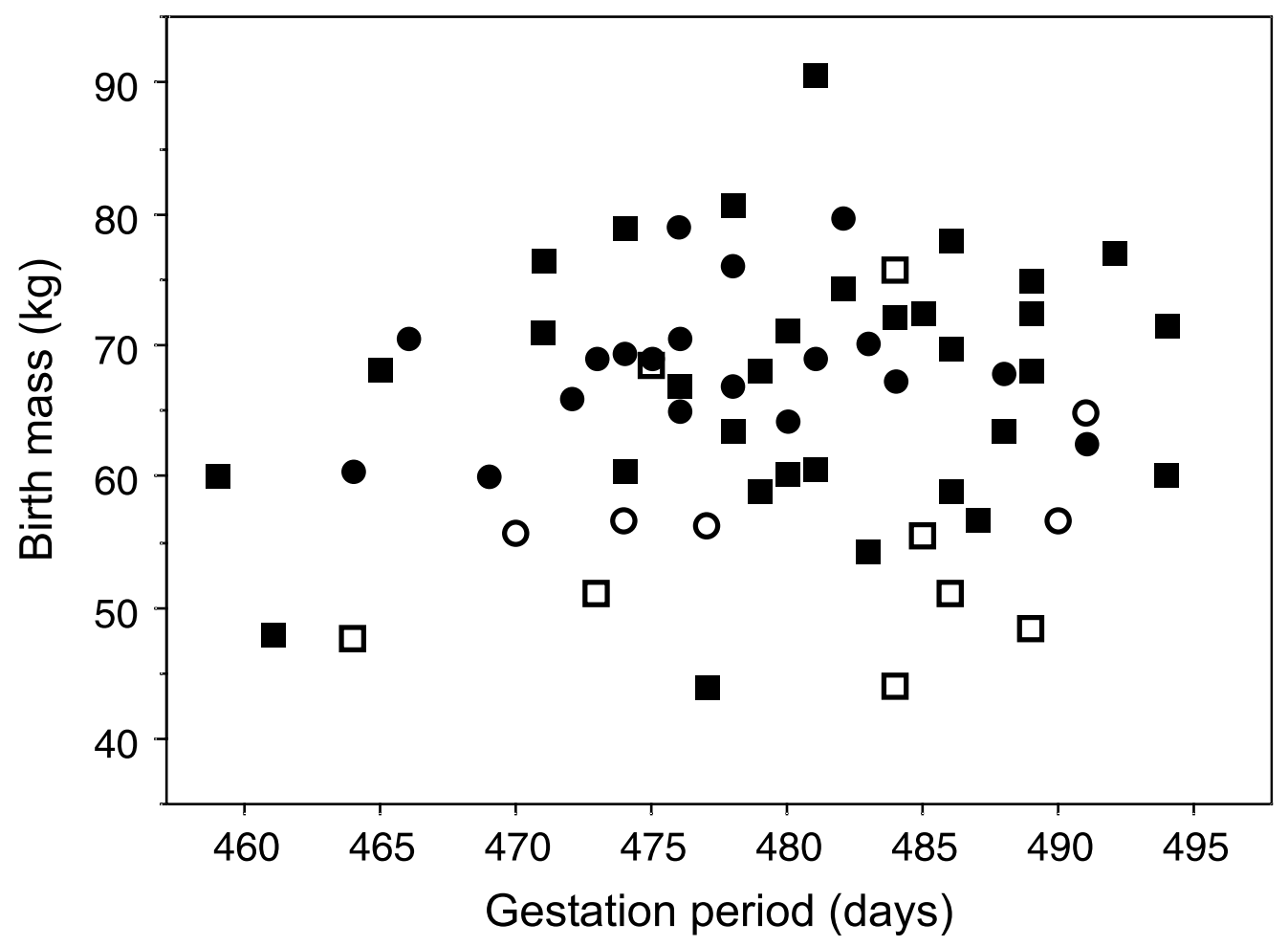

Table 3. Summary of the analyses testing various factors that influence Indian rhinoceros infant mortality.

\begin{tabular}{lrrll}
\hline Source & df & \multicolumn{1}{l}{$\chi^{2}$} & $p$ & $p^{\prime}$ \\
\hline Inbreeding of calf & 1 & 5.57 & 0.018 & 0.070 \\
Status & 2 & 6.76 & 0.034 & 0.360 \\
Outbreeding & 1 & 8.90 & 0.003 & 0.017 \\
Sex & 1 & 0.22 & 0.643 & - \\
Parity & 1 & 5.96 & 0.015 & - \\
Father's age & 1 & 10.51 & 0.001 & - \\
Mother's age & 1 & 9.51 & 0.002 & - \\
Zoo & 25 & 40.88 & 0.024 & 0.011 \\
\hline
\end{tabular}

Note: The factor status combines zoo generation and inbreeding of mother. $p$ values result from the analysis at the individual level (logistic regression) and $p^{\prime}$ values from the analysis at the family $(n=65)$ level (ANOVA). Separate analyses at the individual level with reduced datasets showed that zoo generation $(p=0.001)$ but not inbreeding of mother $(p=$ 0.683 ) influenced infant mortality. A contrast analysis examining the factor status (zoo generation and inbreeding of mother) showed that neither zoo generation $\left(p^{\prime}=0.193\right)$ nor inbreeding of mother $\left(p^{\prime}=0.626\right)$ influenced infant mortality. - , not testable.

severe bottleneck in the first decade of the twentieth century. Most probably, the majority of lethal alleles were purged from this population during that period, which could explain the lack of an increased infant mortality in inbred calves of the Indian rhinoceros. However, recessive alleles with only small negative effects are purged at a slower rate (Hedrick 1994) and therefore probably survived the bottleneck, which could explain the observed reduction in the infant growth rate of inbred calves. However, it is not clear why infant mortality was actually lower in inbred than in non-inbred calves. In other mammals kept in captivity (e.g., in Mexican
Table 4. Percentage of newborn Indian rhinoceroses of different mass classes that died during the first 6 months.

\begin{tabular}{lrl}
\hline Birth mass $(\mathrm{kg})$ & $n$ & Mortality $(\%)$ \\
\hline$<50.0$ & 7 & 57.1 \\
$50.0-59.9$ & 17 & 58.8 \\
$60.0-69.9$ & 31 & 16.1 \\
$70.0-79.9$ & 23 & 13.0 \\
$\geq 80.0$ & 2 & 0.0 \\
\hline
\end{tabular}

and red wolves; Kalinowski et al. 1999), infant mortality decreased with an improved husbandry over the course of time, which coincides with increased inbreeding levels in captive populations. In the Indian rhinoceros, however, infant mortality did not decrease over the course of time.

An infant mortality rate of $11.1 \%$ has been reported for the Chitwan population in the wild (Dinerstein and Price 1991). Since a large fraction of this mortality is caused by tiger predation (e.g., Talukdar and Bora 1998), the intrinsic mortality is probably lower. In the present study, we found a much higher infant mortality rate in captivity $(20.0 \%)$, despite the obvious lack of tiger predation. We suggest three possible explanations for this difference in infant mortality between the captive population and the Chitwan population. One explanation could be that the infant mortality in the wild has been underestimated. In captivity, $85 \%$ of all infant deaths occur on the day of birth (including stillbirths, which often cannot be differentiated from neonatal deaths) or on the subsequent day. If the same is true in the wild, it might be that some births and subsequent neonatal deaths were missed, thus underestimating the infant mortality in the wild. 
Fig. 3. Growth curves of 22 captive Indian rhinoceroses during their first year of life. The insets show a magnified view of the growth during the first 2 months. In the upper figure, dashed lines indicate inbred calves and solid lines indicate non-inbred calves. In the lower figure, dashed lines indicate females and solid lines indicate males. With one exception (marked with a dagger, died at the age of 126 days from torsio coli), lines end because measurements were discontinued.
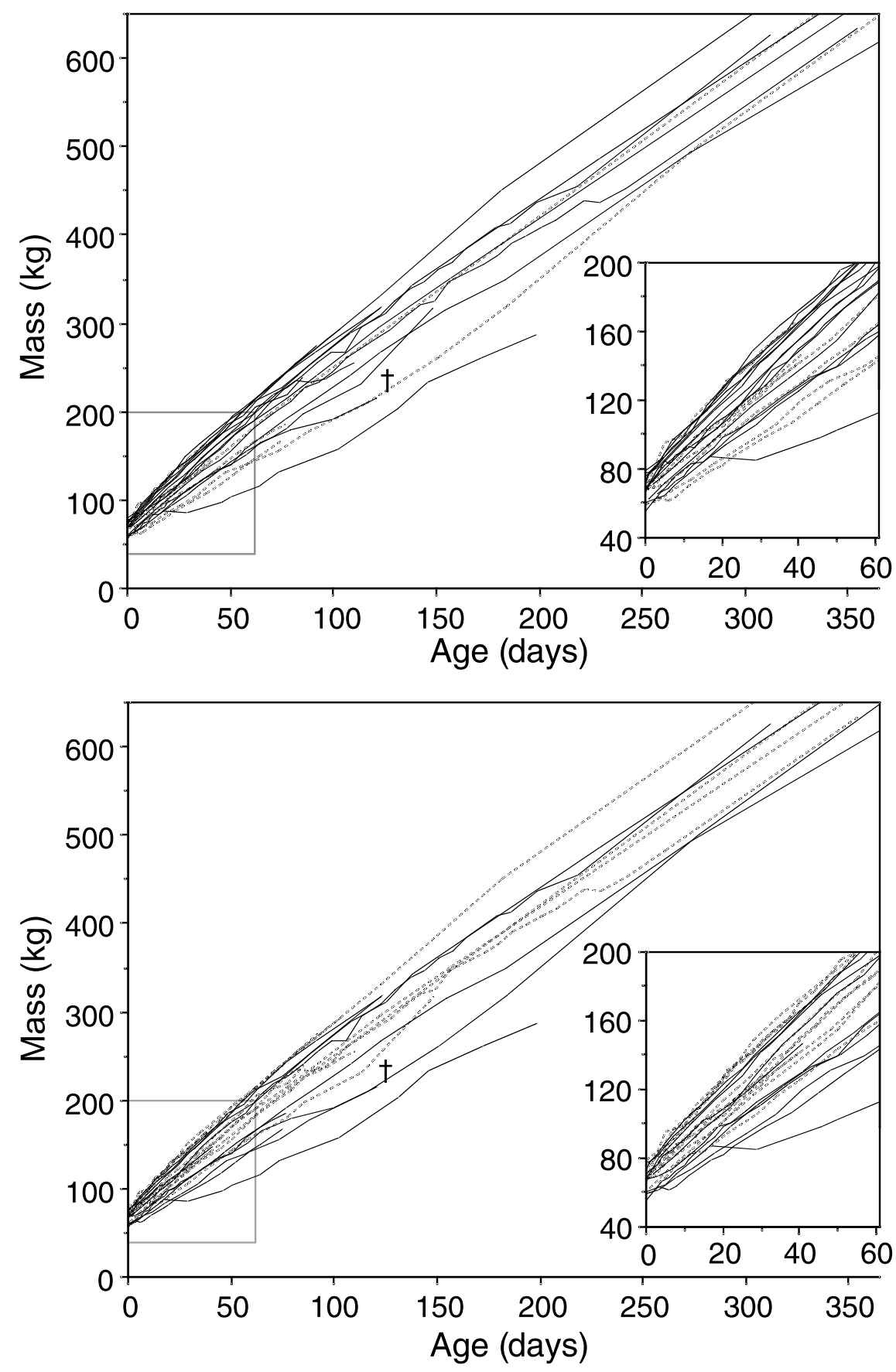

The other two possible explanations are based on the genetic background of the captive population. Inbreeding is known to reduce viability, especially under stress conditions (Bijlsma et al. 2000; Hedrick and Kalinowski 2000). A possible explanation for the findings of the present study could therefore be that the zoo environment is perceived as stressful by dams at parturition or by their neonate calves, resulting in the observed high infant mortality. Along similar lines, it can be argued that the captive population and the Chitwan population probably have a different genetic variability. In contrast with the Chitwan population, which is genetically quite variable (Dinerstein and McCracken 1990), the Kaziranga population, and therefore also a major part of the zoo population, is probably genetically quite homogenous as a consequence of the severe bottleneck in the first decade of the twentieth century; in fact, Merenlender et al. (1989) found no genetic variation among three individuals from the Kaziranga population. It could be possible that the high infant mortality observed in the captive population is caused by its inferred high level of homozygosity, an effect similar to that suggested 
Table 5. Summary of the reduced AN(C)OVAs testing various factors that influence Indian rhinoceros growth rate.

\begin{tabular}{lrllll}
\hline Source & df & MS & $F$ & $p$ & $p^{\prime}$ \\
\hline Inbreeding of calf & 1 & 0.0778 & 7.33 & 0.019 & 0.025 \\
Status & 1 & 0.0168 & 1.58 & 0.232 & 0.153 \\
Sex & 1 & 0.0216 & 2.03 & 0.180 & - \\
Father's age (covariate) & 1 & 0.0170 & 1.60 & 0.230 & - \\
Zoo & 2 & 0.0140 & 1.32 & 0.304 & 0.034 \\
Error & 12 & 0.0106 & & & \\
\hline
\end{tabular}

Note: $p$ values result from the analysis at the individual level and $p^{\prime}$ values from the analysis at the family $(n=8)$ level. During stepwise reduction, the factors outbreeding, parity, and mother's age were eliminated. The factor status was equivalent to zoo generation because no mother of an offspring with known growth rate was inbred. - , not testable.

for the cheetah, Acinonyx jubatus (O'Brien et al. 1985). However, unlike the cheetah (Wielebnowski 1996), captive Indian rhinoceroses show no increase in infant mortality with further inbreeding. Thus, it may be that the Kaziranga-descended captive population of the Indian rhinoceros has an even lower heterozygosity than the cheetah.

\section{Outbreeding}

Outbred offspring (i.e., calves with one parent from the Chitwan population and the other from the Kaziranga population) had a higher infant mortality rate and a shorter gestation period than non-outbred offspring.

Outbred offspring were produced by one male from the Chitwan population (three offspring) and five females from the Chitwan population (four females with two offspring each and one female with one offspring). Except for the female with one offspring, each of these parents had one offspring that died; the increased mortality of the outbred offspring was therefore not the result of a very high mortality rate in a subset of parents from the Chitwan population.

The increased infant mortality rate of outbred offspring could be caused by a partial genetic incompatibility between animals from the Chitwan population and those from the Kaziranga population. So far, it is not known whether these outbred individuals are fertile or not. Of the seven outbred individuals that were alive in captivity on 31 December 2001, four were mature, but none of them had reproduced.

Since no data are available for the gestation periods of Indian rhinoceros from the Chitwan population, we can only guess that individuals from the Chitwan population may generally have a shorter gestation period and that, therefore, individuals with mixed origins also have a shorter gestation period.

The results of the present study support the hypothesis that individuals from the Chitwan and Kaziranga populations are differentiated, confirming findings on differences in skull morphology between individuals from the two populations (Groves 1993).

\section{Sexual dimorphism}

The present study is the first to provide accurate measurements for adult mass and shoulder height in the Indian rhinoceros for a larger number of individuals. It must be kept in mind, however, that all individuals measured have lived in captivity for at least some time. Conditions in zoos and wild parks probably differ from those in the wild, for example with regard to food supply and the possibility or need to walk long distances. It is therefore important to compare the present data with those obtained from animals in the wild. Unfortunately, only one study provides fairly detailed morphometric data on Indian rhinoceroses in the wild (Chitwan population; Dinerstein 1991). The shoulder height of males from the wild $(172 \pm 14 \mathrm{~cm}, n=4)$ was very similar to what we found for captive animals; the shoulder height of females (149 $\pm 15 \mathrm{~cm}, n=3$ ) was smaller than the one that we found. The sexual dimorphism in shoulder height in captive animals (1.08:1) therefore seems to be somewhat smaller (not significantly) than that in animals from the wild population (1.15:1). The sexual dimorphism quoted by Dinerstein (1991) for captive individuals (males $1000 \mathrm{~kg}$ heavier and more than $25 \mathrm{~cm}$ taller than females) is clearly exaggerated.

In comparison, the two African rhinoceros species show contrasting sexual dimorphism. The partially nomadic black rhinoceros (Diceros bicornis) shows no sexual dimorphism (individuals of both sexes are reported to weigh 700-1100 kg; Laurie 1982; Owen-Smith 1988). On the other hand, in the white rhinoceros (Cerathoterium simum), males defend territories, and with a mass of $2000-2300 \mathrm{~kg}$, they are $30-40 \%$ heavier than females (Laurie 1982; Owen-Smith 1988). With "some degree of range exclusivity" (Laurie 1982, p. 307) and a mass dimorphism of $1.28: 1$, the Indian rhinoceros is intermediate between the two African species in both aspects.

The present study shows that the pronounced mass dimorphism in adult Indian rhinoceroses is not yet visible in birth mass and subsequent infant growth. We therefore suggest that the sexual dimorphism in adults is the result of a longer growth period and later maturity in males rather than a difference in growth rate between the sexes. In captivity, males reach maturity at an age of 7-8 years, which is almost twice the age at which females reach maturity (Wirz-Hlavacek et al. 1999). Observations of Indian rhinoceroses in the wild suggest that the onset of actual reproduction in males is even later; Dinerstein and Price (1991, p. 406) reported that "all but one" of the breeding males observed in Chitwan National Park were older than 15 years.

In contrast with other ungulates such as African elephants, Loxodonta africana, and Indian cattle, Bos indicus (Singh et al. 1965; Dhillon et al. 1970; Lee and Moss 1986), interbirth intervals after the birth of a male calf and after the birth of a female calf did not differ in the Indian rhinoceros. Lactation lasts approximately 18 months; no difference between the sexes has been reported. This suggests that there are no differential costs between the sexes during gestation and early lactation, which could have explained the small male bias in the sex ratio at birth (Wirz-Hlavacek et al. 2001). In the wild, however, sons seem to stay longer with their mothers than do daughters. They are chased away by the mother just before the birth of the next calf (Laurie 1982).

\section{Other observations}

As in many other mammals, birth mass, infant mortality, and infant growth in the Indian rhinoceros were strongly influenced by the parity. The observed difference of $16 \%$ in birth mass between primiparous and multiparous neonates is relatively large compared with other species that generally give birth to single offspring: central European humans, 3\% (Hosemann 1948); lesser kudu (Tragelaphus imberbis), 7\% 
(S. Zschokke and B. Steck, unpublished data); dairy cattle, $8 \%$ (Tzalis 1977); pygmy hippopotamus (Choeropsis liberiensis), 12\% (Zschokke and Steck 2001).

Infant mortality rates were lower for older fathers. In the wild, males start breeding much later than in captivity; thus, it is possible that there was no selection pressure for young males to produce high-quality offspring. However, it is unclear by which mechanism the low age of the father could decrease offspring quality. A possible explanation could be that in captivity, low-quality males were allowed to reproduce, which in the wild would have a low probability of surviving to breeding age.

The observed gestation period is very close to the one predicted by allometric formulae. The formula of Blueweiss et al. (1978) (gestation $=66.2 M_{\text {female }}{ }^{0.26}$ ) yields a gestation time for the Indian rhinoceros of 464 days, and the formula of Calder (1982) (gestation $=147 M_{\text {neonate }}{ }^{0.28}$ ) yields a gestation time of 472 days ( $M$ denotes the mass of the mother or the neonate in kilograms). This close agreement with the empirical value of 479 is remarkable, since the data used to derive both formulae did not include any rhinoceros species (Leitch et al. 1959; Sacher and Staffeldt 1974).

Unfortunately, measurements of mass and size were discontinued in many zoos; much of the data used in this study were collected in the 1960s and 1970s. Owing to practical difficulties in weighing the animals, most mass record series of juvenile Indian rhinoceroses break off at masses of around $300 \mathrm{~kg}$, and only few series continue beyond a mass of $500 \mathrm{~kg}$ (cf. Fig. 3). Adult individuals were often only weighed when they were put in a crate for transport. These two facts made proper comparisons of masses and sizes between Indian rhinoceroses from the Kaziranga and Chitwan populations impossible. To allow such comparisons in the future, it is therefore essential that measurements, especially on growth rates and adult size, continue to be taken and recorded whenever possible.

\section{Conclusions}

The results of the present study support the hypothesis that the Kaziranga population is strongly inbred and genetically highly monomorphic. The lack of negative effects of inbreeding of mother and offspring suggests that inbreeding avoidance in the Indian rhinoceros may be not as important as it is in other species. Furthermore, we show that offspring of Chitwan $\times$ Kaziranga matings have an increased mortality. This suggests that the two populations of the Indian rhinoceros may be genetically differentiated. Until more is known about the genetic relationship between the two populations, it would therefore be advisable to discontinue matings between individuals from the two populations and to encourage matings among individuals from the Chitwan population.

\section{Acknowledgements}

We are very grateful to the following zoos for providing data: Mumbai, India; Bronx, New York; Cincinnati, Ohio; Dvur Kralové, Czech Republic; Gauhati, India; Metrozoo, Miami, Fla.; Montgomery, Ala.; Philadelphia, Pa.; Rolling Hills, Kans.; San Diego Wild Animal Park, Calif.; Stuttgart, Germany; Tama, Tokyo, Japan; Toronto, Ont., Canada; Whipsnade Wild Animal Park, U.K.; and Yokohama, Japan. Special thanks go to Gabriele Hlavacek (Basel Zoo) for providing the studbook data, Randy Rieches (San Diego Wild Animal Park), Belinda Reser (Smithsonian National Zoological Park, Washington, D.C.), Marianne Holtkötter (Wilhelma Zoological-Botanical Gardens, Stuttgart), and Friederike von Houwald (Basel Zoo) for providing additional data and Beatrice Steck, Gerry Guldenschuh, Hans-Peter Rusterholz, Martin Haase, Peter Stoll, and an anonymous referee for fruitful discussions and comments on the manuscript.

\section{References}

Andersson, M. 1994. Sexual selection. Princeton University Press, Princeton, N.J.

Baillie, J., and Groombridge, B. 1996. 1996 IUCN red list of threatened animals. IUCN, Gland, Switzerland.

Ballou, J.D. 1983. Calculating inbreeding coefficients from pedigrees. In Genetics and conservation: a reference for managing wild animal and plant populations. Edited by C.M. Schonewald-Cox, S.M. Chambers, B. MacBryde, and W.L. Thomas. Benjamin/ Cummings, Menlo Park, Calif. pp. 509-520.

Ballou, J.D., and Ralls, K. 1982. Inbreeding and juvenile mortality in small populations of ungulates: a detailed analysis. Biol. Conserv. 24: 239-272.

Barrett, S.C.H., and Charlesworth, D. 1991. Effects of a change in the level of inbreeding on the genetic load. Nature (Lond.), 352: 522-524.

Baur, B., and Baur, A. 1992. Reduced reproductive compatibility in Arianta arbustorum (Gastropoda) from distant populations. Heredity, 69: 65-72.

Baur, B., and Studer, P. 1995. Inbreeding in captive Indian rhinoceros. Int. Zoo Yearb. 34: 205-211.

Bhatia, C.L., and Desai, J.H. 1975. Breeding the Indian rhinoceros at Delhi zoological park. In Breeding endangered species in captivity. Edited by R.D. Martin. Academic Press, London. pp. $303-$ 307.

Bijlsma, R., Bundgaard, J., and Boerema, A.C. 2000. Does inbreeding affect the extinction risk of small populations?: predictions from Drosophila. J. Evol. Biol. 13: 502-514.

Blanford, W.T. 1891. The fauna of British India, including Ceylon and Burma. Mammalia. Taylor and Francis, London.

Blueweiss, L., Fox, H., Kudzma, V., Nakashima, D., Peters, R., and Sams, S. 1978. Relationships between body size and some life history parameters. Oecologia, 37: 257-272.

Buechner, H.K., Mackler, S.F., Stroman, H.R., and Xanten, W.A. 1975. Birth of an Indian rhinoceros Rhinoceros unicornis at the National Zoological Park, Washington. Int. Zoo Yearb. 15: 160-165.

Calder, W.A., III. 1982. The pace of growth: an allometric approach to comparative embryology and post-embryonic growth. J. Zool. (1965-1984), 198: 215-225.

Charlesworth, D., and Charlesworth, B. 1987. Inbreeding depression and its evolutionary consequences. Annu. Rev. Ecol. Syst. 18: $237-268$.

Chowdhury, T. 1966. A note on breeding Indian rhinoceroses, Rhinoceros unicornis, at Gauhati Zoo. Int. Zoo Yearb. 6: 197.

Clutton-Brock, T.H. 1991. The evolution of parental care. Princeton University Press, Princeton, N.J.

Coltman, D.W., Bowen, W.D., and Wright, J.M. 1998. Birth weight and neonatal survival of harbour seal pups are positively correlated with genetic variation measured by microsatellites. Proc. R. Soc. Lond. B Biol. Sci. 265: 803-809.

Crnokrak, P., and Roff, D.A. 1999. Inbreeding depression in the wild. Heredity, 83: 260-270. 
Dhillon, J.S., Acharya, R.M., Tiwana, M.S., and Aggarwal, S.C. 1970. Factors affecting the interval between calving and conception in Hariana cattle. Anim. Prod. 12: 81-87.

Dinerstein, E. 1991. Sexual dimorphism in the greater one-horned rhinoceros (Rhinoceros unicornis). J. Mammal. 72: 450-457.

Dinerstein, E., and McCracken, G.F. 1990. Endangered greater onehorned rhinoceros carry high levels of genetic variation. Conserv. Biol. 4: 417-422.

Dinerstein, E., and Price, L. 1991. Demography and habitat use by greater one-horned rhinoceros in Nepal. J. Wildl. Manage. 55: 401-411.

Dutta, A.K. 1991. Unicornis: the Great Indian one-horned rhinoceros. Konark Publishers, Delhi.

Foose, T., van Strien, N., and Rookmaaker, K. 2000. Asian rhino areas and estimates. Asian Rhinos, 3: 20-21.

Groves, C.P. 1993. Testing rhinoceros subspecies by multivariate analysis. In Rhinoceros biology and conservation. Edited by O.A. Ryder. Zoological Society of San Diego, San Diego, Calif. pp. 92100.

Hagenbeck, C.-H. 1969. Notes on the artificial rearing of a Great Indian rhinoceros, Rhinoceros unicornis, at Hamburg Zoo. Int. Zoo Yearb. 9: 99-101.

Hagenbeck, D. 1966. Report on the hand-rearing of an Indian rhinoceros, Rhinoceros unicornis, at Hamburg Zoo. Int. Zoo Yearb. 6: $82-87$.

Hedrick, P.W. 1994. Purging inbreeding depression and the probability of extinction: full sib mating. Heredity, 73: 363-372.

Hedrick, P.W., and Kalinowski, S.T. 2000. Inbreeding depression in conservation biology. Annu. Rev. Ecol. Syst. 31: 139-162.

Hlavacek, G., and Studer, P. 2002. International studbook for the Greater one-horned rhinoceros Rhinoceros unicornis Linné, 1758. Update 31 December 2001. Basel Zoo, Basel, Switzerland.

Hosemann, H. 1948. Schwangerschaftsdauer und Neugeborenengewicht. Arch. Gynaek. 176: 109-123.

Jonauskas, R., and Liparte, E. 2000. The analysis on the weights of the wilder Great one-horned rhinoceroses (Rhinoceros unicornis) in India and Nepal compared to Great one-horned rhinoceroses at the Zoological Gardens in Europe. Available at http://www.unicongmbh.com/\%7Erhinoceros/english.html (accessed on 17 January 2001).

Kalinowski, S.T., Hedrick, P.W., and Miller, P.S. 1999. No inbreeding depression observed in Mexican and red wolf captive breeding programs. Conserv. Biol. 13: 1371-1377.

Krishne Gowda, C.D. 1969. Breeding the great Indian rhinoceros, Rhinoceros unicornis, at Mysore Zoo. Int. Zoo Yearb. 9: 101-102.

Lacy, R.C., Petric, A., and Warneke, M. 1993. Inbreeding and outbreeding in captive populations of wild animal species. In The natural history of inbreeding and outbreeding: theoretical and empirical perspectives. Edited by N.W. Thornhill. University of Chicago Press, Chicago. pp. 352-374.

Lang, E.M. 1961. Beobachtungen am Indischen Panzernashorn (Rhinoceros unicornis). Zool. Gart. 25: 369-409.

Lang, E.M. 1967. Einige biologische Daten vom Panzernashorn (Rhinoceros unicornis). Rev. Suisse Zool. 74: 603-607.

Lang, E.M., Leutenegger, M., and Tobler, K. 1977. Indian rhinoceros births in captivity. Int. Zoo Yearb. 17: 237-238.

Laurie, A. 1982. Behavioural ecology of the greater one-horned rhinoceros (Rhinoceros unicornis). J. Zool. (1965-1984), 196: 307-341.

Laurie, A., Lang, E.M., and Groves, C.P. 1983. Rhinoceros unicornis. Mamm. Species, 211: 1-6.

Laurie, W.A. 1979. The ecology of the Greater one-horned rhinoceros. Ph.D. thesis, University of Cambridge, Cambridge.
Lee, P.C., and Moss, C.J. 1986. Early maternal investment in male and female elephant calves. Behav. Ecol. Sociobiol. 18: 353 361.

Leitch, I., Hytten, F.E., and Billewicz, W.Z. 1959. The maternal and neonatal weights of some mammalia. Proc. Zool. Soc. Lond. 133: $11-28$.

Marshall, T.C., and Spalton, J.A. 2000. Simultaneous inbreeding and outbreeding depression in reintroduced Arabian oryx. Anim. Conserv. 3: 241-248.

McCullagh, P., and Nelder, J.A. 1989. Generalized linear models. 2nd ed. Chapman and Hall, London.

Merenlender, A.M., Woodruff, D.S., Ryder, O.A., Kock, R., and Váhala, J. 1989. Allozyme variation and differentiation in African and Indian rhinoceroses. J. Hered. 80: 377-382.

Molur, S., Sukumar, R., Seal, U., and Walker, S. 1995. Workshop report: population and habitat viability assessment of the Great Indian one-horned rhinoceros. CBSG, Coimbatore, India.

O'Brien, S.J., Roelke, M.E., Marker, L., Newman, A., Winkler, C.A., Meltzer, D., Colly, L., Evermann, J.F., Bush, M., and Wildt, D.E. 1985. Genetic basis for species vulnerability in the cheetah. Science (Washington, D.C.), 227: 1428-1434.

Owen-Smith, R.N. 1988. Megaherbivores: the influence of very large body size on ecology. Cambridge University Press, Cambridge.

Ralls, K. 1977. Sexual dimorphism in mammals: avian models and unanswered questions. Am. Nat. 111: 917-937.

Ralls, K., Brugger, K., and Ballou, J. 1979. Inbreeding and juvenile mortality in small populations of ungulates. Science (Washington, D.C.), 206: 1101-1103.

Ralls, K., Ballou, J.D., and Templeton, A. 1988. Estimates of lethal equivalents and the cost of inbreeding. Conserv. Biol. 2: 185193.

Reynolds, R.J. 1961. Asian rhinos in captivity. Int. Zoo Yearb. 2: $17-42$.

Rookmaaker, L.C. 1998. The rhinoceros in captivity. SPB Academic Publishing, Den Haag, the Netherlands.

Rookmaaker, L.C. 1999. Records of the rhinoceros in Northern India. Saeugetierk. Mitt. 44: 51-78.

Rookmaaker, L.C. 2000. Records of the rhinoceros in Pakistan and Afghanistan. Pak. J. Zool. 32: 65-74.

Rosenthal, R., and Rosnov, R.L. 1985. Contrast analysis: focused comparisons in the analysis of variance. Cambridge University Press, Cambridge.

Ryhiner, P. 1961. Auf Tierfang durch die Welt. Horst Erdmann, Herrenalb, Germany.

Saccheri, I.J., Brakefield, P.M., and Nichols, R.A. 1996. Severe inbreeding and rapid fitness rebound in the butterfly Bicyclus anynana (Satyridae). Evolution, 50: 2000-2013.

Sacher, G.A., and Staffeldt, E.F. 1974. Relation of gestation time to brain weight for placental mammals: implications for the theory of vertebrate growth. Am. Nat. 108: 593-615.

SAS Institute Inc. 1997. JMP ${ }^{\circledR}$ user's guide. SAS Institute Inc., Cary, N.C.

Singh, O.N., Singh, R.N., and Srivastava, R.R.P. 1965. Study in post-partum interval to first service in Tharparkar cattle. Indian J. Vet. Sci. 35: 245-248.

Talukdar, B.K., and Bora, N. 1998. Tiger predation of rhinoceroses. Oryx, 32: 96.

Templeton, A.R. 1986. Coadaptation and outbreeding depression. In Conservation biology: the science of scarcity and diversity. Edited by M.E. Soulé. Sinauer Associates, Sunderland, Mass. pp. 105-116. 
Tobler, K. 1993. International studbook for the Great Indian rhinoceros Rhinoceros unicornis (Linné 1758). 7th ed. Basel Zoo, Basel, Switzerland.

Tong, E.H. 1960. The breeding of the Great Indian rhinoceros at Whipsnade Park. Int. Zoo Yearb. 2: 12-15.

Tzalis, K. 1977. Geburtsgewicht, Entwicklung, Mastleistung und Schlachtkörperwert von Erstlingskälbern im Vergleich zu später geborenen. Ph.D. thesis, Universität Hohenheim, Stuttgart, Germany.

von Houwald, F. 2001. Foot problems in Indian rhinoceroses (Rhinoceros unicornis) in Zoological Gardens: macroscopic and microscopic anatomy, pathology, and evaluation of the causes. Ph.D. thesis, Universität Zürich, Zürich, Switzerland.

Waser, N.M. 1993. Population structure, optimal outbreeding, and assortative mating in angiosperms. In The natural history of inbreeding and outbreeding: theoretical and empirical perspectives. Edited by N.W. Thornhill. University of Chicago Press, Chicago. pp. 173-199.
Wielebnowski, N. 1996. Reassessing the relationship between juvenile mortality and genetic monomorphism in captive cheetahs. Zoo Biol. 15: 353-369.

Wirz-Hlavacek, G., Zschokke, S., and Studer, P. 1999. International studbook for the Greater one-horned rhinoceros Rhinoceros unicornis (Linné 1758). 10th ed. Basel Zoo, Basel, Switzerland.

Wirz-Hlavacek, G., Zschokke, S., and Studer, P. 2001. International studbook for the Greater one-horned rhinoceros Rhinoceros unicornis Linné, 1758. 11th ed. Basel Zoo, Basel, Switzerland.

Zschokke, S., and Steck, B. 2001. Tragzeit und Geburtsgewicht beim Zwergflußpferd, Hexaprotodon liberiensis. Zool. Gart. 71: 57-61.

Zschokke, S., Studer, P., and Baur, B. 1998. Past and future breeding of the Indian rhinoceros in captivity. Int. Zoo News, 45: 261-276. 